\title{
Non-participation and attrition in a longitudinal study of civilians exposed to the January 2015 terrorist attacks in Paris, France
}

Cécile Vuillermoz ${ }^{1 *}$, Lise Eilin Stene ${ }^{2}$, Lydéric Aubert ${ }^{3}$, Yvon Motreff $^{4,5}$, Philippe Pirard ${ }^{5}$, Thierry Baubet ${ }^{6,7,8}$, Sophie Lesieur ${ }^{4}$, Pierre Chauvin ${ }^{4}$ and Stéphanie Vandentorren ${ }^{3,4}$

\begin{abstract}
Background: Non-participation and attrition are rarely studied despite being important methodological issues when performing post-disaster studies. A longitudinal survey of civilians exposed to the January 2015 terrorist attacks in Paris, France, was conducted 6 (Wave 1) and 18 months (Wave 2) after the attacks. We described nonparticipation in Wave 1 and determined the factors associated with attrition in Wave 2.

Methods: Multivariate logistic regression models were used to compare participants in both waves with those who participated in the first wave only. Analyses were performed taking the following factors into account: sociodemographic characteristics, exposure to terror, peri-traumatic reactions, psychological support, perceived social support, impact on work, social and family life, and mental health disorders. Characteristics of new participants in Wave 2 were compared with participants in both waves using a chi-square test.

Results: Of the 390 persons who were eligible to participate in the survey, 190 participated in Wave 1 (participation rate: 49\%). The most frequently reported reason for non-participation was to avoid being reminded of the painful event $(32 \%, n=34 / 105)$. In Wave 2, 67 were lost to follow-up, 141 people participated, of whom 123 participated in Wave 1 (re-participation rate: 65\%) and 18 were new. Attrition in Wave 2 was associated with socio-demographic characteristics (age, French origin) and location during the attacks, but not with terror exposure or mental health disorders. Compared with those who participated in both waves, new participants declared less social and psychological support since the attacks.

Conclusions: Attrition at 6 months was not associated with exposure to terror or mental health disorders, which indicates that any bias in future analyses on IMPACTS on mental health outcomes will be limited. Our findings suggest the importance of adapting similar surveys for people of foreign origin and of improving strategies to avoid attrition of younger people, for example by using social media, peers, and the educational environment. The present study also revealed that a high level of exposure to terror and a lack of social and psychological support after a terrorist event could impede individuals' participation in similar surveys in the short term.
\end{abstract}

Keywords: Attrition, Non-participation, Bias selection, Terrorist attack survey, Mental health survey

\footnotetext{
* Correspondence: cecile.vuillermoz@inserm.fr

${ }^{1}$ Centre National de la Recherche Scientifique (CNRS), Centre Maurice

Halbwachs (CNRS-UMR8097, EHESS, ENS), F75014 Paris, France

Full list of author information is available at the end of the article
}

(C) The Author(s). 2020 Open Access This article is licensed under a Creative Commons Attribution 4.0 International License, which permits use, sharing, adaptation, distribution and reproduction in any medium or format, as long as you give appropriate credit to the original author(s) and the source, provide a link to the Creative Commons licence, and indicate if changes were made. The images or other third party material in this article are included in the article's Creative Commons licence, unless indicated otherwise in a credit line to the material. If material is not included in the article's Creative Commons licence and your intended use is not permitted by statutory regulation or exceeds the permitted use, you will need to obtain permission directly from the copyright holder. To view a copy of this licence, visit http://creativecommons.org/licenses/by/4.0/ The Creative Commons Public Domain Dedication waiver (http://creativecommons.org/publicdomain/zero/1.0/) applies to the data made available in this article, unless otherwise stated in a credit line to the data. 


\section{Background}

In January 2015, a series of terrorist attacks in the greater Paris area commenced with the massacre of members of the satirical magazine Charlie Hebdo by two terrorists in the city centre. A few hours later, a third terrorist injured an individual in a nearby town, and the next morning killed a police officer in another suburban town. The following day, he took hostages in a grocery store and killed 4 of them [1-3]. In total, these three terrorists killed 17 people and injured 20 people in 3 days.

In order to investigate the impact of these terrorist attacks on civilians and on rescue workers' mental health and social functioning, as well as to assess the social support and mental health care they received in short- and in long-term care, Santé publique France (the French National Public Health Agency), with the support of the Greater Paris regional health agency, launched the IMPACTS survey (the French acronym for Investigation of Trauma Consequences in People Exposed to the January 2015 Terrorist Attacks and their Support and Mental care) [4]. The second wave of the survey was implemented with the collaboration of INSERM (the French National Institute of Health and Medical Research).

Despite the frequency of terrorist attacks worldwide and increased numbers in recent years in Western Europe, few epidemiological surveys have studied their health impact because of methodological and ethical issues [5]. In particular, their unpredictability makes it difficult to begin an investigation, while conducting research on potentially traumatized individuals immediately after the event requires rigorous ethical considerations and healthcare follow-up procedures.

The few studies that have been conducted on individuals involved in terrorist attacks rarely examine methodological issues like selection bias. Generally speaking, non-participants in health surveys are more likely to be male, single or divorced, with a lower educational level, unemployed, and/or with poor health [6-9]. In mental health surveys, non-participation may be associated with the type and the level of exposure and with the outcome of interest itself [10]. In particular, in studies on traumatic events, people with severe physical disabilities or injuries and people with mental health disorders are less likely to participate $[11,12]$. Furthermore, disasterrelated factors such as exposure to terror may influence participation. For example, people with a low exposure level may feel that their participation is less legitimate. Similarly, those with a high exposure level may prefer to avoid being reminded of the event [13].

In longitudinal surveys, attrition (loss to follow-up) may be associated with demographics and socioeconomic characteristics, health status, health-related behaviours, and healthcare experiences [14-16]. In the specific case of longitudinal trauma surveys, attrition may be higher in people whose physical and/or mental health deteriorates over time, especially in the case of intentional trauma like terrorism, war or torture [17-20].

To enhance participation and to minimize the risk of bias, previous research proposed open cohorts, where eligible persons who do not initially participate in the first wave of a study may be re-contacted and included in future waves [21]. IMPACTS was designed as an open cohort study, the initial waves being conducted 6 and 18 months after the January 2015 attacks (specifically, between June and October 2015, and between June and October 2016).

In the present study, we aimed to describe reasons why some civilians exposed to terror did not wish to participate in Wave 1 of IMPACTS, to determine the factors associated with attrition in Wave 2 in order to describe any selection bias, and to compare characteristics of new participants in Wave 2 with participants of both waves in order to examine the benefit of the open cohort design. To do this, we studied whether sociodemographic characteristics at baseline, terror exposure characteristics, peri-traumatic reactions, psychological support given by professionals, social support and certain diagnosed mental health disorders were different between 1) participants in both waves, 2) participants in Wave 1 who were subsequently lost to follow-up in Wave 2, and 3) participants not included at Wave 1 but who participated in Wave 2.

\section{Methods}

\section{Design and population of IMPACTS survey}

The design of the IMPACTS survey has been described elsewhere [4]. Wave 1 was conducted between June and October 2015 among four civilian sub-populations:

1) Persons listed either by the authorities, or by CUMP (Medico-Psychological Emergency Unit) volunteers as injured, a hostage or a witness who had to flee the scene because their lives were threatened $(N=410)$. They were contacted by telephone by health professionals;

2) Members of the editorial staff of the Charlie Hebdo magazine $(N=15)$. The IMPACTS survey was introduced to them face-to-face by the survey's investigation team. Afterward, they were contacted by email;

3) Residents and workers within a $100-\mathrm{m}$ radius of the sites of the attacks $(N=884)$. Letters were sent to 1295 households, accounting for an estimated 2635 residents. Using INSEE (the French National Institute of Statistics and Economic Studies) data, the investigation team estimated that $10 \%$ of the resident population $(264 / 2635)$ were at home during the attacks. Letters were also sent to 72 
companies where approximately 620 workers were present during the attacks;

4) Civilians identified by other victims through snowball sampling [22]. They were contacted by telephone by health professionals.

The inclusion criteria for IMPACTS were: being a civilian from one of the 4 categories mentioned above, aged 16 or over, and meeting one of the 4 A (i.e., stressor) criteria for Posttraumatic Stress Disorder (PTSD) as set out in the Diagnostic and Statistical Manual of Mental Disorders, Fifth edition (DSM-5) [23]. In terms of the latter, the following four exposure categories were defined:

- directly threatened: suffering from physical injuries, taken hostage, or present at the scene of the event scene and exposed to at least one of the following situations: eye contact with/heard the voice of/talked with the terrorists; seen a weapon pointed directly at them.

- indirectly threatened: both directly present at the scene during the attacks - but not in the category "directly threatened" - and having at least one of the following exposures: seen/heard someone else being threatened/being injured/dying; seen blood or inert/ dead bodies; touched injured/inert/dead bodies, smelled gunpowder.

- witnesses: at home or working within a 100-m radius of the events and not in the categories "directly/indirectly threatened"

- close relatives of those who were murdered, injured and/or taken hostage.

After inclusion, in both study waves, participants were interviewed face-to-face by trained trauma psychologists. A training day was arranged for all psychologist: theoretical training, presentation of the tools, practical workshops in small groups.

Wave 2 was conducted 1 year after Wave 1 (i.e., 18 to 22 months after the events), between June and October 2016. All the participants who participated in Wave 1 were re-contacted by phone by 26 of the 31 psychologists who intervened in Wave 1. Additionally, people who responded to the inclusion questionnaire and were eligible for the study but did not participate in Wave 1 were contacted for Wave 2 by phone.

\section{Study variables}

As mentioned above, non-participation and attrition may be associated with socio-demographic characteristics [69], high-level exposure to a traumatic event [10-13], and poor mental or physical health (as a direct consequence of the traumatic event in question or not). In addition to these factors, for the present study, we made the hypothesis that survey participants interviewed by media about the January 2015 terrorist attacks before either wave, may have been either less apprehensive or, alternatively, more reluctant to talk again about their experience .

\section{Sociodemographic characteristics}

Sociodemographic data collected in both waves included: sex, age at time of Wave 1, French origin (yes/no), educational level (higher or lower than high-school diploma), occupational status (employed/unemployed) and living with someone (yes/no) at the time of Wave 1.

\section{Terror exposure and peri-traumatic reactions}

Terror exposure was measured using several indicators: geographic exposure (less than $10 \mathrm{~m}$ from terrorist(s), very close or in the next room to the attack, in a neighbouring building or street, or elsewhere), exposure category (see above), and perceived terror exposure as measured by an analogical scale ranging from 0 ("I was not really exposed") to 10 ("I was one of the people most exposed").

Peri-traumatic reactions were measured by the Shortness of breath, Tremulousness, Racing heart and Sweating scale (STRS), which is a 13-item scale (ranging to 0 to 4) that provides a retrospective score of the somatic manifestations of fear [24], and the Peritraumatic Dissociative Experience Questionnaire (PDEQ), which is a 10-item (ranging from 0 to 4) questionnaire that measures peri-traumatic dissociative symptoms [25].

\section{Psychological support}

All participants were interviewed about the psychological support they received (by a professional or a volunteer) in the $48 \mathrm{~h}$ after the events, between $48 \mathrm{~h}$ and 1 week after, and more than 1 week after. In both waves, participants were also asked if they had had regular care, support or follow-up with a psychologist or psychiatrist after the events. In both waves, they were also interviewed about their overall satisfaction with the psychological support they received from professionals or volunteers, to cope with stress since the events.

\section{Perceived social support}

In both waves, at the time of the interview(s), all participants were asked about their current perceived feeling of isolation and about current emotional, financial and material support.

\section{Impact on work, social and family life}

The Sheehan Disability Scale was used to assess functional impairment in three domains: work/school, social, and family life. Each domain score was divided into 5 categories: 0 (unimpaired), 1-3 (lightly impaired), 4-6 (moderately impaired), 7-9 (notably impaired) and 10 
(severely impaired) [26]. We recoded each score to a binary variable "declared a score greater than 4 or not".

\section{Experience with media}

In Wave 1, participants were asked if they had been contacted and/or interviewed by any media about their experiences with the January 2015 terrorist attacks.

\section{Mental health disorders}

For both waves, modules from the Mini-International Neuro-psychiatric Interview (MINI) v6 questionnaire were used to assess current PTSD, depression, and anxiety disorders (agoraphobia, social phobia, panic disorder or general anxiety) [27]. In addition, in both waves, interviewers used the Clinical Global Impression - Severity Scale (CGI - S) to rate the current severity of respondents' general mental health state relative to their past clinical experience with similarly diagnosed patients. This scale has 7 possible ratings (normal, not at all ill, borderline mentally ill, mildly ill, moderately ill, markedly ill, severely ill, and among the most extremely ill patient) [28].

\section{Statistical analyses}

We performed a logistic regression analysis to compare participants lost to follow-up with those who participated in both waves (the dependent variable was "lost to follow-up" (yes/no)). All variables associated with the outcome with a $p$-value $<0.10$ were included in an initial multivariate model and then manually backwardselected. Because of the small number of new participants in Wave 2, we could not perform multivariate regression to compare them with people who had participated in both waves. Comparisons between participants in both waves and new participants in Wave 2 were performed using Chi-square tests (or exact Fisher tests when frequencies were low) for the categorical variables and using Mann-Whitney's tests for the continuous variables (due to the non-normal distribution of the continuous variables), with a two-sided statistical significance level of 0.05 . All analyses were carried out using $R$ (version 3.5.2) statistical software.

The dataset supporting the conclusions of this article is included within its additional file.

\section{Results}

Non-participation in wave 1

1) Authorities and caregivers listed 410 people as being injured, hostages or witnesses who had to flee the scene because their lives were threatened. In Wave 1, the survey team attempted to contact the 249 persons in this list with an available telephone number, in order to solicit their participation in IMPACTS. Of these, 48 were unreachable. The other 201 were all contacted by a member of the survey team (specifically a psychologist or health professional). Fifteen did not meet the inclusion criteria (Fig. 1). Among the 186 who did, 24 declined to participate (13\%) and 162 agreed (agreement rate: $87 \%$ ).

2) Of the 15 members of the editorial staff of Charlie $H e b d o, 6$ responded to the inclusion questionnaire by e-mail. Five of these members agreed to participate in IMPACTS and 1 person declined (agreement rate: $83 \%$ ).

3) Of the 884 residents and workers believed to be present within a 100 - $\mathrm{m}$ radius of the attacks when they occurred, 259 (29\%) responded to the

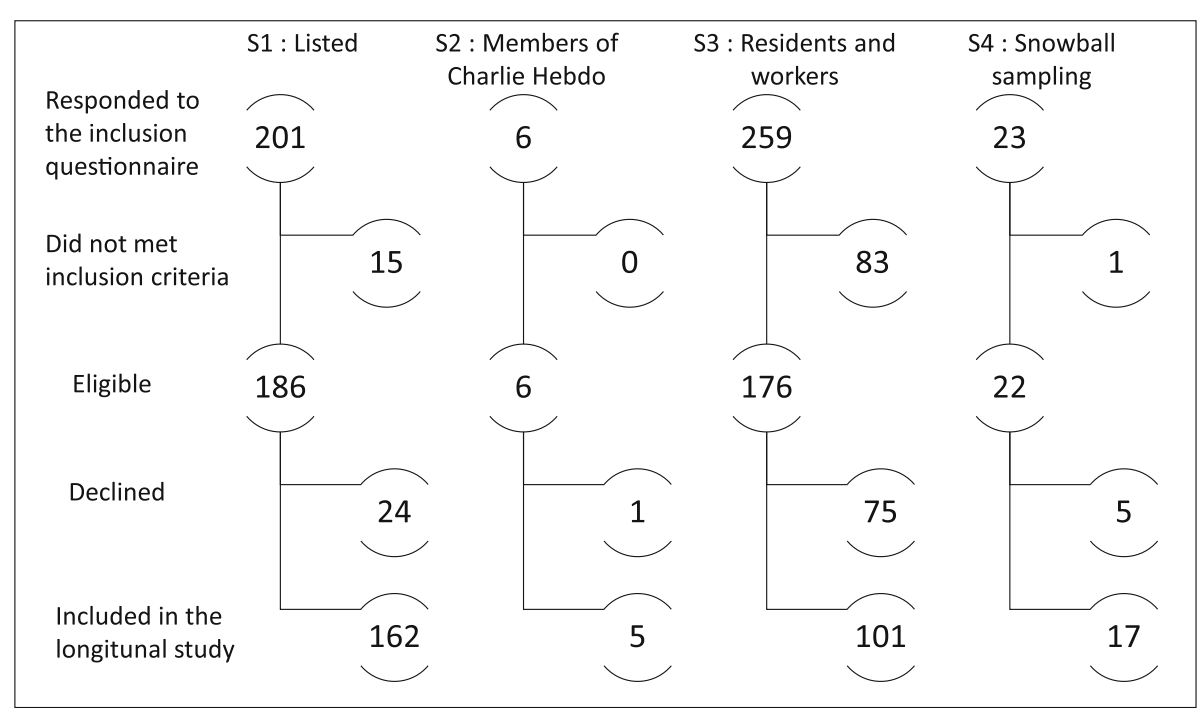

Fig. 1 Process for inclusion of participants in the IMPACTS survey according to the different data sources used in the survey 
invitation letters. Of these, 83 (32\%) were excluded because they did not meet the inclusion criteria. Of the 176 who were eligible, 75 (43\%) declined to participate in IMPACTS, while 101 agreed (agreement rate: $57 \%$ ).

4) Twenty-three people were identified as close relatives of people involved using snowball sampling. Of these 1 did not meet the inclusion criteria. Five of the remaining $22(23 \%)$ declined to participate in IMPACTS while 17 agreed (agreement rate: $77 \%$ ).

To summarize, in Wave 1 , of the 489 people who responded to the inclusion questionnaire, 99 did not meet the inclusion criteria (20\%). Of the remaining eligible 390, 105 declined to participate (27\%) while 285 agreed they would participate in the longitudinal study (global agreement rate to participate in IMPACTS: 73\%).

However, of the 285 who initially agreed to participate, 190 participated in Wave 1, 47 only participated in Wave 2, 45 did not in the end participate in either wave, and 3 were secondarily excluded because of inaccurate reporting (Fig. 2). The actual participation rate in Wave 1 was therefore 49\% (190/390).

Among the 105 persons who declined to participate, the reasons cited were a desire not to be reminded of the painful event $(32 \%, n=34)$, lack of time $(16 \%, n=$ 17), not feeling concerned $(15 \%, n=16)$ and the fear of data leakage $(5 \%, n=5)$. Thirty-three people $(31 \%)$ did not provide any reason for their refusal. Participants were younger than people who declined $(39 \mathrm{y} / \mathrm{o}, 52 \mathrm{y} / \mathrm{o}$, respectively, $p<0.001)$. The gender ratio did not differ between participants and those who declined (1.53 vs 1.30 respectively, $p=0.527$ ).

\section{Attrition in wave 2 \\ Participation rate}

For the second wave, of the 190 participants in Wave 1, 123 (65\%) were re-interviewed, $16(8 \%)$ were unreachable, $41(22 \%)$ declined to participate and $10(5 \%)$ were not interviewed (reasons unknown) or they cancelled the interview. Among those who declined, 17 (42\%) did not provide any reason, 7 (17\%) reported not having enough time, $5(12 \%)$ preferred to forget the events and to move on without being reminded of them again, $4(10 \%)$ said it was still too painful to talk about what had happened, $3(7 \%)$ said that their participation was useless, $1(2 \%)$ moved away from Paris, and 4 (10\%) gave other reasons.

\section{Factors associated with attrition in wave 2}

In univariate analysis, attrition was significantly higher in younger people $\left(\mathrm{OR}_{[31-50]}=0.4195 \% \mathrm{CI}[0.20-0.84], \mathrm{OR}_{[251]}=\right.$ $0.2795 \% \mathrm{CI}[0.11-0.65], p=0.007)$, in those who had nonFrench origin $\left(\mathrm{OR}=3.2 \quad{ }_{95 \%} \mathrm{CI}[1.01-10.21], \quad p=0.049\right)$ (Table 1), those who were impacted by the attacks in the suburban towns of Paris (as opposed to the Paris city centre attack at Charlie Hebdo) $\left(\mathrm{OR}=2.13{ }_{95 \%} \mathrm{CI}[1.13-4.01], p=\right.$ 0.018). Attrition was higher in those who had no support after i) $48 \mathrm{~h}$, ii) at 1 week iii) and/or more than 1 week following the events $\left(\mathrm{OR}=2.00{ }_{95 \%} \mathrm{CI}[1.01-3.93], p=0.046\right)$. Attrition was lower in those who lived alone $(\mathrm{OR}=0.42$ $\left.{ }_{95 \%} \mathrm{CI}[0.20-0.92], p=0.030\right)$ and in those who reported that

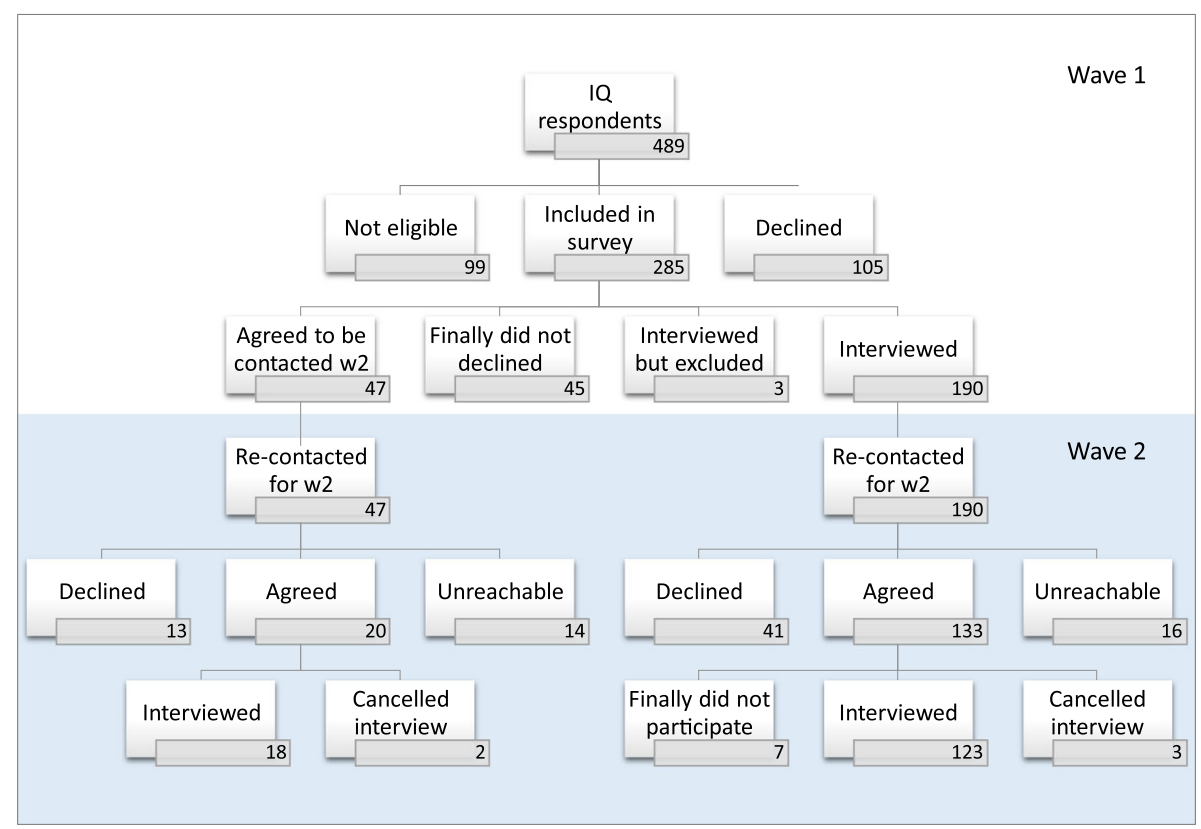

Fig. 2 Flow chart of IMPACTS survey (waves 1 and 2) 
Table 1 Comparison of participants in both waves to those who participated only in Wave 1

\begin{tabular}{|c|c|c|c|c|c|c|c|c|c|}
\hline & \multicolumn{2}{|c|}{$\begin{array}{c}\text { Total } \\
N=190\end{array}$} & \multicolumn{2}{|c|}{ Lost to follow-up $N=67$} & \multicolumn{2}{|c|}{$\begin{array}{c}\text { Waves } \\
1 \& 2 N=123\end{array}$} & \multirow[t]{2}{*}{ OR } & \multirow[t]{2}{*}{$\mathrm{Cl}$} & \multirow[t]{2}{*}{$p$-value } \\
\hline & $\mathrm{N} / \mathrm{m}$ & $\% / s d$ & $\mathrm{~N} / \mathrm{m}$ & $\% / s d$ & $\mathrm{~N} / \mathrm{m}$ & $\% / s d$ & & & \\
\hline \multicolumn{10}{|l|}{ Socio-demographics } \\
\hline Female Gender & 115 & 60.5 & 40 & 59.7 & 75 & 61.0 & 0.95 & {$[0.85-1.74]$} & 0.864 \\
\hline \multicolumn{10}{|l|}{ Age at time of terrorist attack: } \\
\hline mean & 41.8 & 13.6 & 38.8 & 14.3 & 43.5 & 12.9 & & & \\
\hline $\min -\max$ & \multicolumn{2}{|c|}{$19-84$} & \multicolumn{2}{|c|}{$19-84$} & \multicolumn{2}{|c|}{$23-79$} & & & \\
\hline [18-30] & 49 & 25.8 & 26 & 38.8 & 23 & 18.7 & ref & & 0.007 \\
\hline$[31-50]$ & 94 & 49.5 & 30 & 44.8 & 64 & 52.0 & 0.41 & {$[0.20-0.84]$} & \\
\hline$\geq 51$ & 47 & 24.7 & 11 & 16.4 & 36 & 29.2 & 0.27 & {$[0.11-0.65]$} & \\
\hline Educational Level < high-school diploma & 57 & 30.2 & 24 & 35.8 & 33 & 27.0 & 0.66 & {$[0.35-1.26]$} & 0.210 \\
\hline Unemployed & 34 & 17.9 & 14 & 20.9 & 20 & 16.3 & 1.36 & {$[0.64-2.91]$} & 0.427 \\
\hline Living alone & 46 & 24.2 & 10 & 14.9 & 36 & 29.3 & 0.42 & {$[0.20-0.92]$} & 0.030 \\
\hline Non-French origin & 13 & 6.8 & 8 & 11.9 & 5 & 4.1 & 3.20 & {$[1.01-10.21]$} & 0.049 \\
\hline \multicolumn{10}{|l|}{ Terror exposure } \\
\hline Event location outside of Paris (vs Paris) & 131 & 68.9 & 39 & 58.2 & 92 & 74.8 & 2.13 & {$[1.13-4.01]$} & 0.019 \\
\hline \multicolumn{10}{|l|}{ Geographic exposure: } \\
\hline Less than $10 \mathrm{~m}$ & 20 & 10.5 & 6 & 9.0 & 14 & 11.4 & 1.39 & {$[0.32-6.08]$} & 0.639 \\
\hline Very close, next room & 64 & 33.7 & 23 & 34.3 & 41 & 33.3 & 1.82 & {$[0.53-6.25]$} & \\
\hline Neighbouring building & 89 & 46.8 & 34 & 50.7 & 55 & 44.7 & 2.01 & {$[0.61-6.67]$} & \\
\hline Elsewhere & 17 & 8.9 & 4 & 6.0 & 13 & 10.6 & ref & & \\
\hline \multicolumn{10}{|l|}{ Objective exposure: } \\
\hline Directly threatened & 58 & 30.5 & 22 & 32.8 & 36 & 29.3 & 0.86 & [0.37-2.00] & 0.516 \\
\hline Indirectly threatened & 82 & 43.2 & 27 & 40.3 & 55 & 44.7 & 0.38 & {$[0.09-1.61]$} & \\
\hline Close relative of victims & 14 & 7.4 & 3 & 4.5 & 11 & 8.9 & 0.69 & {$[0.31-1.54]$} & \\
\hline Witness & 36 & 18.9 & 15 & 22.4 & 21 & 17.1 & ref & & \\
\hline Perceived terror exposure (0-10) & 6.3 & 3.0 & 6.1 & 3.1 & 6.4 & 3.0 & 0.97 & {$[0.88-1.07]$} & 0.518 \\
\hline \multicolumn{10}{|l|}{ Peri-traumatic reactions } \\
\hline PDEQ (0-40) & 15.5 & 10.5 & 14.2 & 10.8 & 16.2 & 10.3 & 0.98 & {$[0.95-1.01]$} & 0.226 \\
\hline STRS (0-52) & 22.5 & 11.6 & 20.9 & 12.9 & 23.4 & 10.9 & 0.98 & {$[0.96-1.01]$} & 0.170 \\
\hline \multicolumn{10}{|l|}{ Sheehan disability scale } \\
\hline Work (impact $\geq 4$ ) & 83 & 45.1 & 19 & 28.8 & 64 & 54.2 & 0.34 & {$[0.18-0.65]$} & 0.001 \\
\hline Social life (impact $\geq 4$ ) & 75 & 39.5 & 22 & 32.8 & 53 & 43.1 & 0.65 & {$[0.35-1.20]$} & 0.168 \\
\hline Family life, home responsibilities (impact $\geq 4$ ) & 66 & 34.7 & 23 & 34.3 & 43 & 35.0 & 0.97 & {$[0.52-1.82]$} & 0.930 \\
\hline \multicolumn{10}{|l|}{ Psychological support } \\
\hline No psychological support (after 48 h, 1w, or > 1w) & 46 & 24.2 & 22 & 32.8 & 24 & 19.5 & 2.00 & {$[1.01-3.93]$} & 0.046 \\
\hline No regular psychological follow-up after attack & 144 & 76.2 & 55 & 83.3 & 89 & 72.4 & 1.91 & {$[0.89-4.08]$} & 0.094 \\
\hline Dissatisfaction with psychological support from professionals & 56 & 32.6 & 22 & 39.3 & 34 & 29.3 & 1.56 & {$[0.80-3.05]$} & 0.192 \\
\hline \multicolumn{10}{|l|}{ Media impact } \\
\hline Contacted by media regarding the event & 116 & 61.1 & 40 & 59.7 & 76 & 61.8 & 0.92 & {$[0.50-1.68]$} & 0.778 \\
\hline Interviewed by media regarding the event & 63 & 34.8 & 28 & 43.8 & 35 & 29.9 & 1.82 & {$[0.97-3.43]$} & 0.063 \\
\hline \multicolumn{10}{|l|}{ Social support } \\
\hline Feeling alone & 27 & 14.2 & 7 & 10.4 & 20 & 16.3 & 0.60 & {$[0.24-1.50]$} & 0.277 \\
\hline No perceived moral/emotional support & 2 & 1.1 & 1 & 1.5 & 1 & 0.8 & 1.85 & {$[0.11-30.03]$} & 0.666 \\
\hline
\end{tabular}


Table 1 Comparison of participants in both waves to those who participated only in Wave 1 (Continued)

\begin{tabular}{|c|c|c|c|c|c|c|c|c|c|}
\hline & \multicolumn{2}{|c|}{$\begin{array}{c}\text { Total } \\
N=190 \\
\end{array}$} & \multicolumn{2}{|c|}{ Lost to follow-up $N=67$} & \multicolumn{2}{|c|}{$\begin{array}{c}\text { Waves } \\
1 \& 2 N=123 \\
\end{array}$} & \multirow[t]{2}{*}{ OR } & \multirow[t]{2}{*}{$\mathrm{Cl}$} & \multirow[t]{2}{*}{ p-value } \\
\hline & $N / m$ & $\% / s d$ & $\mathrm{~N} / \mathrm{m}$ & $\% / s d$ & $\mathrm{~N} / \mathrm{m}$ & $\% / s d$ & & & \\
\hline No perceived financial/material support & 37 & 19.5 & 11 & 16.4 & 26 & 21.1 & 0.73 & {$[0.34-1.60]$} & 0.434 \\
\hline No perceived everyday support & 20 & 10.5 & 6 & 9.0 & 14 & 11.4 & 0.77 & {$[0.28-2.10]$} & 0.603 \\
\hline \multicolumn{10}{|l|}{ Mental health } \\
\hline PTSD (previous month) & 34 & 17.9 & 14 & 20.9 & 20 & 16.3 & 1.36 & {$[0.64-2.91]$} & 0.427 \\
\hline Major depressive disorder (last two weeks) & 20 & 10.5 & 7 & 10.4 & 13 & 10.6 & 0.99 & {$[0.37-2.61]$} & 0.979 \\
\hline Suicide risk (previous month) & 52 & 27.4 & 15 & 22.4 & 37 & 30.1 & 0.67 & {$[0.34-1.34]$} & 0.257 \\
\hline Anxiety disorders (at least one) & 50 & 26.5 & 16 & 23.9 & 34 & 27.9 & 0.91 & {$[0.47-1.73]$} & 0.764 \\
\hline Moderately/markedly/severely ill (CGI) & 55 & 29.4 & 17 & 26.2 & 38 & 31.1 & 0.78 & [0.40-1.53] & 0.476 \\
\hline
\end{tabular}

IMPACTS survey, France, 2015

$N$ Number, $m$ Mean, sd Standard deviation, OR Odds ratio, $C l$ Confidence interval, ref Reference. $P$-value was two-sided statistical significance level of the logistic regression. $P$-values in bold were lesser than 0.10

the events had affected their work moderately or sever$\operatorname{ely}\left(\mathrm{OR}=0.34{ }_{95 \%} \mathrm{CI}[0.18-0.65], p=0.001\right)$. We did not observe significant associations between attrition and other factors assessed in this study (other sociodemographic characteristics, exposure characteristics, medico-psychological support, consumption of tobacco, alcohol or cannabis, social support or mental health). As indicated in the Methods, all variables associated with the outcome with a $p$-value $<0.10$ were included in an initial multivariate analysis. Thus, we also included regular psychological support after the attacks $(p=0.094)$ and being interviewed by media about their experiences with the attacks $(p=0.063)$.

Apart from psychological support after the event and interviews by different media, all study variables were significantly associated with attrition in Wave 2 in multivariate analysis (Table 2). People at least 31 years old participated in both waves significantly more often than younger participants $\left(\mathrm{OR}_{[31-50]}=0.34{ }_{95 \%} \mathrm{CI}[0.15-0.75]\right.$, $\left.\mathrm{OR}_{[251]}=0.14{ }_{95 \%} \mathrm{CI}[0.05-0.40], p<0.001\right)$. Attrition was higher in participants who had non-French origin (OR = $\left.5.83{ }_{95 \%} \mathrm{CI}[1.51-21.52], p=0.009\right)$ and in those who were impacted by the attacks in the suburban towns of Paris (as opposed to the Paris city centre attack at Charlie Hebdo) $\left(\mathrm{OR}=2.19{ }_{95 \%} \mathrm{CI}[1.06-4.53], p=0.033\right)$. Attrition was lower in those who lived alone $(\mathrm{OR}=0.37$ $\left.{ }_{95 \%} \mathrm{CI}[0.15-0.88], p=0.019\right)$ and those who had a Sheehan work score greater than $4\left(\mathrm{OR}=0.47{ }_{95 \%} \mathrm{CI}[0.23-\right.$ 0.97], $p=0.012$ ).

\section{New study participation: wave 2}

Among the 47 eligible civilians who agreed to participate in Wave 2 but not Wave 1, 18 did in fact participate (38\%), 15 (32\%) were unreachable and 14 (30\%) declined when re-contacted for Wave 2 (Fig. 2). The reasons cited by the latter were: "it is still too painful" $(n=3)$, "I prefer to forget these tragic events and to move on without being reminded again" ( $n=3)$, "my participation is useless" $(n=2)$, "I do not have enough time" $(n=2)$. Four did not provide any reason for their non-participation.

The 18 new study participants were significantly more likely to report no regular psychological support or follow-up than those who participated in both waves (72.2\% vs $38.2 \%, p=0.010$ ) (Table 3 ). They were also more likely to feel alone in 2015 after the attacks $(44.4 \%$ vs $16.3 \%, p=0.005$ ) and to report having no moral support when needed $(22.2 \%$ vs $0.8 \%, p=0.001)$. This difference in the level of social support provided was not observed in Wave 2.

Table 2 Multivariate regression analysis of the comparison between those were lost to follow-up and those who participated in both waves

\begin{tabular}{|c|c|c|c|}
\hline & OR & $\mathrm{Cl}$ & $p$-value \\
\hline Age at time of the attack & & & $<0.001$ \\
\hline [18-30] & Ref. & & \\
\hline$[31-50]$ & 0.34 & {$[0.15-0.75]$} & \\
\hline$\geq 51$ & 0.14 & {$[0.05-0.40]$} & \\
\hline Living alone & & & 0.019 \\
\hline No & Ref. & & \\
\hline Yes & 0.37 & {$[0.15-0.88]$} & \\
\hline French Origin & & & 0.009 \\
\hline French origin & Ref. & & \\
\hline Non-French origin & 5.83 & {$[1.51-22.52]$} & \\
\hline Event location & & & 0.033 \\
\hline Paris & Ref. & & \\
\hline Suburban town & 2.19 & {$[1.06-4.53]$} & \\
\hline Sheehan Work score & & & 0.012 \\
\hline$<4$ & Ref. & & \\
\hline$\geq 4$ & 0.41 & {$[0.21-0.83]$} & \\
\hline
\end{tabular}

IMPACTS survey, France, 2015.

$O R$ Odds ratio, $\mathrm{Cl}$ Confidence interval, Ref Reference. $P$-value was the twosided statistical significance level of the logistic regression. 
Table 3 Comparison of participants who participated in both waves with new participants in Wave 2

\begin{tabular}{|c|c|c|c|c|c|c|c|}
\hline & \multicolumn{2}{|c|}{$\begin{array}{c}\text { Total wave } 2 \\
N=141\end{array}$} & \multicolumn{2}{|c|}{$\begin{array}{c}\text { New participants } \\
\quad N=18\end{array}$} & \multicolumn{2}{|c|}{ Wave $1 \& 2 \mathrm{~N}=123$} & \multirow[t]{2}{*}{$p$-value } \\
\hline & $\mathrm{N} / \mathrm{m}$ & $\% / s d$ & $\mathrm{~N} / \mathrm{m}$ & $\% / s d$ & $\mathrm{~N} / \mathrm{m}$ & $\% / s d$ & \\
\hline \multicolumn{8}{|l|}{ Socio-demographics } \\
\hline Female Gender & 82 & 58.2 & 8 & 44.4 & 75 & 61.0 & 0.183 \\
\hline \multicolumn{8}{|l|}{ Age at time of the attack: } \\
\hline mean, sd & 42.9 & 12.9 & 39.1 & 12.0 & 43.5 & 12.9 & 0.205 \\
\hline $\min -\max$ & \multicolumn{2}{|c|}{$21-79$} & \multicolumn{2}{|c|}{$21-60$} & \multicolumn{2}{|c|}{$23-79$} & \\
\hline Educational Level < high-school diploma & 41 & 29.3 & 8 & 44.4 & 33 & 27.0 & 0.130 \\
\hline Unemployed at Wave 2 & 37 & 26.2 & 5 & 27.8 & 32 & 26.0 & 0.999 \\
\hline Living alone at Wave 2 & 46 & 32.6 & 7 & 38.9 & 39 & 31.7 & 0.594 \\
\hline Non-French origin & 8 & 5.7 & 3 & 16.7 & 5 & 4.1 & 0.065 \\
\hline \multicolumn{8}{|l|}{ Terror exposure } \\
\hline Event location outside of Paris (vs Paris) & 39 & 27.7 & 8 & 44.4 & 31 & 25.2 & 0.088 \\
\hline \multicolumn{8}{|l|}{ Geographic exposure: } \\
\hline Less than $10 \mathrm{~m}$ & 20 & 14.2 & 6 & 33.3 & 14 & 11.4 & NA \\
\hline Very close, next room & 46 & 32.6 & 5 & 27.8 & 41 & 33.3 & \\
\hline Neighbouring building & 62 & 44.0 & 7 & 38.9 & 55 & 44.7 & \\
\hline Elsewhere & 13 & 9.2 & 0 & 0 & 13 & 10.6 & \\
\hline \multicolumn{8}{|l|}{ Objective exposure: } \\
\hline Directly threatened & 44 & 31.2 & 8 & 44.4 & 36 & 29.3 & NA \\
\hline Indirectly threatened & 60 & 42.6 & 5 & 27.8 & 55 & 44.7 & \\
\hline Close relative of victims & 11 & 7.8 & 0 & 0 & 11 & 8.9 & \\
\hline Witness & 26 & 18.4 & 5 & 27.8 & 21 & 17.1 & \\
\hline Perceived terror exposure (mean 0-10) & 6.3 & 2.9 & 5.9 & 2.7 & 6.4 & 3.0 & 0.378 \\
\hline \multicolumn{8}{|l|}{ Sheehan disability scale in Wave 2} \\
\hline Work (impact $\geq 4$ ) & 69 & 48.9 & 7 & 38.9 & 62 & 50.4 & 0.452 \\
\hline Social life (impact $\geq 4$ ) & 67 & 47.5 & 8 & 44.4 & 59 & 48.0 & 0.806 \\
\hline Family life, home responsibilities (impact $\geq 4$ ) & 53 & 37.6 & 6 & 33.3 & 47 & 38.2 & 0.798 \\
\hline \multicolumn{8}{|l|}{ Medical/psychological support } \\
\hline No regular psychological support or follow-up since the event & 60 & 42.6 & 13 & 72.2 & 47 & 38.2 & 0.010 \\
\hline Dissatisfaction with psychological support from professionals since the events & 56 & 40.0 & 8 & 47.1 & 48 & 39.0 & 0.526 \\
\hline \multicolumn{8}{|l|}{ Social support } \\
\hline Feeling alone in 2015 & 28 & 19.9 & 8 & 44.4 & 20 & 16.3 & 0.005 \\
\hline Feeling alone in 2016 & 34 & 24.1 & 7 & 38.9 & 27 & 22.0 & 0.117 \\
\hline No perceived moral/emotional support in 2015 & 5 & 3.5 & 4 & 22.2 & 1 & 0.8 & 0.001 \\
\hline No perceived moral/emotional support in 2016 & 6 & 4.3 & 2 & 11.1 & 4 & 3.3 & 0.169 \\
\hline No perceived financial/material support in 2015 & 30 & 21.3 & 4 & 22.2 & 26 & 21.1 & 0.999 \\
\hline No perceived financial/material support in 2016 & 28 & 19.9 & 4 & 22.2 & 24 & 19.5 & 0.757 \\
\hline No perceived support in everyday life 2015 & 18 & 12.8 & 4 & 22.2 & 14 & 11.4 & 0.249 \\
\hline No perceived support in everyday life 2016 & 17 & 12.1 & 3 & 16.7 & 14 & 11.4 & 0.457 \\
\hline \multicolumn{8}{|l|}{ Physical and psychological health } \\
\hline Deterioration of general health state & 27 & 19.1 & 3 & 16.7 & 24 & 19.5 & 0.999 \\
\hline Deterioration of psychological health state & 28 & 19.9 & 2 & 11.1 & 26 & 21.1 & 0.527 \\
\hline Having at least one health problem & 135 & 95.7 & 17 & 94.4 & 118 & 95.9 & 0.627 \\
\hline
\end{tabular}


Table 3 Comparison of participants who participated in both waves with new participants in Wave 2 (Continued)

\begin{tabular}{|c|c|c|c|c|c|c|c|}
\hline & \multicolumn{2}{|c|}{$\begin{array}{c}\text { Total wave } 2 \\
N=141 \\
\end{array}$} & \multicolumn{2}{|c|}{$\begin{array}{c}\text { New participants } \\
\quad N=18 \\
\end{array}$} & \multicolumn{2}{|c|}{ Wave $1 \& 2 \mathrm{~N}=123$} & \multirow[t]{2}{*}{$p$-value* } \\
\hline & $\mathrm{N} / \mathrm{m}$ & $\% / s d$ & $\mathrm{~N} / \mathrm{m}$ & $\% / s d$ & $\mathrm{~N} / \mathrm{m}$ & $\% / s d$ & \\
\hline \multicolumn{8}{|l|}{ Mental health at Wave 2} \\
\hline PTSD (previous month) & 21 & 15.0 & 3 & 17.6 & 18 & 14.6 & 0.721 \\
\hline Major depressive disorder (last two weeks) & 12 & 8.6 & 2 & 11.8 & 10 & 8.1 & 0.641 \\
\hline Suicide risk (previous month) & 57 & 40.7 & 4 & 23.5 & 53 & 43.1 & 0.187 \\
\hline Anxiety disorders (at least one) & 54 & 38.6 & 7 & 41.2 & 47 & 38.2 & 0.814 \\
\hline Moderately/markedly/severely ill (CGI) & 42 & 31.8 & 3 & 33.3 & 39 & 31.7 & 0.839 \\
\hline \multicolumn{8}{|l|}{ Involvement in November 2015 attacks } \\
\hline Directly threatened or witness & 9 & 6.4 & 0 & 0 & 9 & 7.3 & NA \\
\hline Close relative of victims & 16 & 11.3 & 2 & 11.1 & 14 & 11.4 & 0.999 \\
\hline
\end{tabular}

IMPACTS survey, France, 2015-2016

$N$ Number, $m$ Mean, $s d$ Standard deviation, NA Non available. $P$-value was the two-sided statistical significance level of the chi-square test for categorical variables and Mann-Whitney test for continuous variables. $P$-values in bold were lesser than 0.05 )

No significant differences were observed between these new participants and those who participated in both waves in terms of other sociodemographic characteristics, exposure characteristics, medico-psychological support, toxic substance consumption, social support or mental health.

\section{Discussion}

Twenty years after the first study on terrorist attacks in France [29], the IMPACTS survey investigated the impact of the Paris January 2015 terrorist attacks on the mental health and social functioning of civilians involved. The present study enabled us to describe nonparticipation in Wave 1 of the survey and determine the factors associated with attrition in Wave 2. More specifically, this study focused on the number of persons solicited to participate in IMPACTS, on those who initially agreed/declined to participate, and on those who actually participated. Potential participants for IMPACTS came from a variety of sources, with different stakeholder profiles: survivors, residents, workers, witnesses, as well as close relatives of those injured, those taken hostage and those who died. Given that the total number of civilian stakeholders in these terrorist attacks is unknown, it was not possible to compute global participation rates. Among all the people contacted who met the survey's inclusion criteria $(N=390)$, the final participation rate for Wave 1 was $49 \%$. The participation rate for these same people was $65 \%$ in Wave 2.

In the last 20 years, cohort studies dealing with the health impacts of terrorist attacks on civilians have been conducted in the US (following the 11 September, 2001 terrorist attacks), and in Europe (following the 11 March, 2004 train bombings in Madrid, and the Oslo/ Utøya massacre in 2011 [30]). Participations rates in these cohorts ranged from 40 to $70 \%$ in the first study waves, and were generally higher in subsequent waves (50 to $75 \%$ ).

Comparing the participation rates of these studies is unrealistic because of the differing study contexts, designs and populations. If a terrorist attack occurs in a public place and involves the general population, those who are directly threatened may be more heterogeneous than an attack which occurs in specific groups or communities, such as the Utøya island attack where the perpetrator attacked a summer camp hosting members from the Norwegian Labour Party's youth organization [31]. This heterogeneity suggests the need for tailored strategies to recruit representative participants and involves different designs. Indeed, cohorts on this theme have been recruited from Web-enabled panels [32, 33], registries [34], authority lists, healthcare centres [35], and random digit dial telephone surveys [36, 37]. Moreover, some studies have involved only those directly threatened whereas others, like IMPACTS, also involved witnesses, close relatives, residents and workers present during the attacks. For example, the World Trade Center Health Registry (WTCHR) cohort comprised not only people present at the 9/11 attack site itself (workers and volunteers involved in rescue, recovery, clean-up, and other activities) but also residents in Canal Street in lower Manhattan, and students and staff employed at schools south of Canal Street [34]. In addition, the numbers of participants differ greatly between cohorts, ranging from a few hundred to many thousands of participants. For example, the WTCHR cohort enrolled more than 71,000 people exposed to the $9 / 11$ attack [38] while 1589 individuals participated in a longitudinal study after the Madrid train attack [37], and 355 were enrolled in the open cohort of Utøya [21]. The moment when the investigation takes place and the length of time between successive study waves, may influence participation, and is very heterogeneous between 
the cohorts mentioned here. For instance, two of the cohort studies above were based on a nationally representative, web-enabled panel which was collected 10 days after the 9/11 attacks [32,33] while the Utøya cohort interviewed participants for the first time 4 to 5 months after the events [21].

In France, only three studies on terror attacks were conducted in the past, following the 20 bombing and 1 machine-gun attacks that occurred in the country between 1982 and 1987 [29], and another wave of bombing attacks that occurred in 1995 and 1996 [39, 40]. Abenhaim et al. conducted a retrospective cross-sectional survey on 254 survivors listed by the police and medical emergency services after the 1982-1987 terrorist attacks [29]. The participation rate in that study was $78 \%(n=$ 254/324). In Verger et al.'s retrospective cross-sectional study on the 1995-1996 terrorist attacks among people identified as "victims" by the French Terrorism Victim Guarantee Fund [39], the participation rate was $86 \%$ ( $n=196 / 228$ ). Finally, Jehel et al. published a study on the 1995-1996 terrorist attacks among civilians listed by the police department and by an organization that provided psychological and juridical support to the victims [40]. Among the 111 people contacted 6 months after the events, $51 \%$ participated in the first wave, of whom $55 \%$ participated in the second wave one year after.

Attrition in Wave 2 was higher in participants aged 18 to $30 \mathrm{y} / \mathrm{o}$ than in older participants, and in people of nonFrench origin. The latter finding was also observed in the Utøya study for people of non-Norwegian origin [21] and a cohort study of the survivors from the World Trade Center terrorist attack [20]. The age effect has also been observed in health surveys in the French general population [15] and in trauma-related studies [18, 20, 21]. Both results suggest that it is important to develop innovative recruitment strategies for younger participants and for people of non-French origin for future waves of the present study as well as for future studies in the context of other terror attacks. Attrition was higher for participants living in suburban towns, perhaps because of relatively higher recruitment in Paris. Participants exposed to the city-centre attack (Charlie Hebdo) may have had better healthcare management in the wake of the attack because of greater available services in the city of Paris than in its suburbs. Moreover, they may have been more willing to talk to the survey's investigating psychologists and to participate [41]. Indeed, in univariate analysis, those lost-to follow-up were more likely not to have had psychological follow-up after the events. Since attrition did not seem to be a consequence of either the terror exposure level or mental health problems, we hypothesize that the risk of under- or over-estimation of the prevalence of mental health disorders due to the consequences of the attacks in Wave 2 was limited.
Although impacted by the small numbers of individuals involved, the comparison between the profiles of new participants in Wave 2 and people who participated in both waves highlights the value of conducting an open cohort study to be able to include specific victim profiles at a later date. We found that new participants were more socially isolated: they were more likely to feel alone and to report no moral or emotional support at Wave 1 (but less likely at Wave 2), which strongly suggests that their initial social isolation might have negatively influenced their decision to participate initially. This result was consistent with the study of Stene et al. that indicated that non-participation was associated with less social support [21]. Furthermore, new participants were more likely not to have had any regular psychological support after the attacks. Finally, although the small sample size prevented the possibility of performing a significance test, new participants were more likely to have been directly threatened or geographically very close to the terrorist(s), i.e. they were more likely to be those most exposed.

The IMPACTS survey had strengths and limitations in terms of recruitment. The first limitation is that the initial questionnaire was in French only and this may have excluded potential participants who did not speak French. Second, the investigation period for both waves (between June and October) may not have been the most suitable choice as it covered the summer holidays, when many people go on vacation. Furthermore, during the second study wave, another terror attack occurred in the city of Nice, during the traditional Bastille Day fireworks festival (14 July, 2016) where 500 people were injured and 86 were killed [42]. Even though most, if not all of the people exposed to the Paris attacks were not physically in Nice when this attack occurred, they were very probably exposed to images and testimonies widely publicised on the media. It is well known that reexposure can reactivate PSTD symptoms [43, 44]. Accordingly, the Nice attack may have influenced participation in Wave 2 of IMPACTS.

The strengths of the IMPACTS survey in terms of recruitment were, first, the combination of several lists from different authorities, the comprehensive research carried out to estimate the number of residents and workers who were potentially present when the events took place, and the pro-active search for people which were not listed (mainly witnesses and close relatives). Second, the IMPACTS survey focused a great deal on ethical considerations, something which may have maximized participation. In particular, all the interviewers were psychologists trained in trauma. They worked at avoiding re-activation of PSTD symptoms and referred participants to selected mental health services if needed. A hotline was created to facilitate the sharing of 
information to and between collaborating psychologists and psychiatrists, and to help orient participants with specific psychological needs. Furthermore, as much as possible, participants were interviewed during both waves by the same psychologist. For participants who had moved residence between the two waves, the interviewer proposed meeting them at their new home or doing the interview by video.

\section{Study limitations}

The present study has other limitations. First, the total number of civilians exposed was unknown because the total numbers of residents and workers present at the time of the attacks was not available. Furthermore, the total number of people close to the injured, to those taken hostage and to those who died was also unavailable. In the absence of such a denominator, the "true" participation rate could not be estimated. Nor was it possible to estimate bias due to the non-participation of unidentified, uninformed people who met the inclusion criteria ("to be involved in the terrorist attacks of January 2015 according to the exposure criteria A for Posttraumatic Stress Disorder (PTSD) of the DSM-5"). However, we can reasonably suppose that all those directly exposed were identified and listed by the authorities.

Second, the number of new participants in the second wave was small. Consequently, we were not able to generate reliable estimates and robust comparisons with those who participated only in Wave 2. Finally, only declarative data were available and we cannot exclude the possibility that some of these data were subject to recall or reporting bias.

\section{Conclusions}

The lower level of participation of younger people (i.e., $<31 \mathrm{y} / \mathrm{o}$ ), of people of non-French origin, and In those who were impacted by the attacks in the suburban towns of Paris (as opposed to the Paris city centre attack at Charlie Hebdo) suggests that other recruitment strategies are necessary to improve participation by these subpopulations in future waves of the IMPACTS study and in future surveys following terrorist attacks in general. Indeed, following the IMPACTS study, some recommendations have already been made for strategies to encourage such participation. The first is to display information posters in town council halls, local social service structures, and community-based organizations' premises (for the young, the elderly, migrants, minorities, etc.) in areas exposed to terror, as well as in Medico-Psychological Emergency Units (called CUMP in France), and common consultation sites. The second is to involve social media $[45,46]$. For younger people in particular, this could be achieved by mobilizing educational institutions and professionals. A third possible strategy to encourage participation, is the implementation of community-based collaborative research processes which have been proven to increase trust between research partners and participants, and increase engagement of hard-to-reach populations [47]. In 2013, a symposium suggested integrating research and evaluation into disaster-response planning [48].

In the absence of existing guidelines on health research after mass trauma, we would recommend that future guidelines need to ensure that great attention is paid to the ethical and methodological issues and challenges involved in any study investigating the consequences of mass trauma on mental health and social functioning. Notably, we suggest i) to make efforts to collect information of non-participants in an ethically respectful way, ii) to use an open cohort design in longitudinal post-terror studies in order to allow for later participation among survivors who are unable to participate in the first wave during the early aftermath of the attack, and iii) to systematically estimate levels of and factors associated with non-participation and attrition to take into account potential selection bias in the interpretation of the findings.

\begin{abstract}
Abbreviations
Cl: Confidence Interval; CUMP: French acronym for medical-psychological emergency unit (Cellule d'Urgence Médico-Psychologique in French); DSM5: Diagnostic and Statistical Manual of Mental Disorders, fifth edition; IMPACTS: French acronym for Investigation of Trauma Consequences in People Exposed to the January 2015 Terrorist Attacks and their Support and Mental care (Investigation des manifestations traumatiques post-attentats et de la prise en charge thérapeutique et de soutien des personnes impliquées dans les attentats de janvier 2015 en Île-de-France in French); MINI: MiniInternational Neuro-psychiatric Interview; OR: Odds ratio; PDEQ: Peritraumatic Dissociative Experience Questionnaire; PTSD: Posttraumatic Stress Disorder; STRS: Shortness of breath, Tremulousness, Racing heart and Sweating scale; WTCHR: World Trade Center Health Registry
\end{abstract}

\section{Acknowledgements}

The authors are most grateful to all the study participants for their involvement especially given the very difficult context for them, and to all the interviewers. The authors would like to acknowledge the support from the national French agency for public health as well as the regional agency for health of Paris area: Anne Gallay, Thierry Cardoso, Anne Laporte, Jean Claude Desenclos, Clothilde Hachin, Naine Isserlis, Michel Gentile, Laurent Kosorotoff, Martial Mettendorf, Claude Evin, and François Bourdillon for generously contribution their time and energy to the conduct of IMPACTS study. A special thanks to Laurent Bernard-Brunel, Alexandra Botero, JeanMichel Coq, Nathalie Cholin, Nicolas Dantchev, Elise Neff, Marc Grohens, Aurelia Rochedreux, Toufik Selma, Laure Zeltner and Julien Sonnesi for their field investigation. We wish to thank the members of the scientific committee of the study as Bruno Falissard, Nathalie Prieto, Louis Jehel, François Ducrocq, Humbert Boisseaux, Jean Jacques Chavagnat. We wish to thank Jude Sweeney for his careful reading of the final manuscript.

\section{Authors' contributions}

CV designed this study, performed all statistical analysis, and drafted the manuscript. LES assisted in interpretation of the analysis and revision of the manuscript. LA, TB supervised the data collection and designed the first wave of the IMPACTS survey, and contributed to the revision of the manuscript. YM, PP contributed to the questionnaire conceptualization of the first wave of the IMPACTS survey and contributed to the revision of the manuscript. SL contributed to the questionnaire conceptualization and the data collection of one of the Wave 2 of the IMPACTS survey, and in the 
revision of the manuscript. PC contributed to the survey design and the data collection of Wave 2 of the IMPACTS survey, and supervised the writing of the paper. SV designed, supervised the questionnaire conceptualization and the data collection of the two waves of the IMPACTS survey, and supervised the data analysis, the interpretation of the analysis and the writing of the manuscript. All authors reviewed the draft versions of this manuscript, and read and approved the final version.

\section{Funding}

The IMPACTS survey was financially funded by the "Fondation d'Aide aux Victimes" and was coordinated by Santé publique France and the Greater Paris regional health agency (ARS-IdF). CV's post-doctoral was funded by the "Fondation d'Aide aux Victimes". LES's contribution was funded by The Research Council of Norway (p.nr. 288321). The funding bodies had no role in the design of the study, data collection, analysis, interpretation of data, and writing the manuscript.

\section{Availability of data and materials}

The data that support the findings of this study are available from The French Public Health Agency (Santé Publique France), but restrictions apply to the availability of these data, which were used under license for the current study, and so are not publicly available. Data are however available from the authors upon reasonable request and with permission of The French Public Health Agency.

\section{Ethics approval and consent to participate}

The IMPACTS survey received approval from the Committee of Ethics and Deontology (CED) of Santé Publique France in 2015, and from CNIL (the French National Commission on Informatics and Liberties, notice No. 915262), CPP (the French ethical research committee, notice No. 3283) and CCTIRS (the French Advisory Committee on Information Processing in Material Research in the Field of Health, notice No. 150522B-31). Written informed consent was obtained from all participants.

\section{Consent for publication}

\section{Not applicable.}

\section{Competing interests}

The authors declare that they have no competing interests.

\section{Author details}

${ }^{1}$ Centre National de la Recherche Scientifique (CNRS), Centre Maurice Halbwachs (CNRS-UMR8097, EHESS, ENS), F75014 Paris, France. ${ }^{2}$ Norwegian centre for violence and traumatic stress studies (NKVTS), Oslo, Norway. ${ }^{3}$ Santé publique France, Direction des régions, F94415 Saint-Maurice, France. ${ }^{4}$ Department of Social Epidemiology, INSERM, Sorbonne Université, Institut Pierre Louis d'Epidémiologie et de Santé Publique, F75012 Paris, France. ${ }^{5}$ Santé publique France, Direction des maladies non transmissibles et traumatismes, F94415 Saint-Maurice, France. ${ }^{6}$ CESP Inserm 1178, Université Paris 13, Paris, France. ${ }^{7}$ Psychopathology Department for Children, Adolescents, General Psychiatry and Specialized Addiction, APHP Hôpital Avicenne, F93009 Bobigny, France. ${ }^{8}$ Centre national de Ressources et de Résilience (CNRR), Paris, France.

\section{Received: 12 December 2019 Accepted: 28 February 2020} Published online: 14 March 2020

\section{References}

1. Vandentorren S, Paty A-C, Baffert E, Chansard P, Caserio-Schönemann C. Syndromic surveillance during the Paris terrorist attacks. Lancet. 2016;387: 846-7.

2. Carli P, Pons F, Levraut J, Millet B, Tourtier J-P, Ludes B, et al. The French emergency medical services after the Paris and Nice terrorist attacks: what have we learnt? Lancet. 2017;390:2735-8.

3. De Stefano C, Orri M, Agostinucci JM, Zouaghi H, Lapostolle F, Baubet T, et al. Early psychological impact of Paris terrorist attacks on healthcare emergency staff: a cross-sectional study. Depress Anxiety. 2018;35:275-82.

4. Vandentorren S, Pirard P, Sanna A, Aubert L, Motreff Y, Dantchev N, et al. Healthcare provision and the psychological, somatic and social impact on people involved in the terror attacks in January 2015 in Paris: cohort study. Br J Psychiatry. 2018;212:207-14.
5. Gradus JL, Marx BP, Sloan DM. Investigating the aftermath of terror: fundamental outcomes, methodological choices, and future directions. Psychosom Med. 2016;78:522-4.

6. Cottler LB, Zipp JF, Robins LN, Spitznagel EL. Difficult-to-recruit respondents and their effect on prevalence estimates in a epidemiologic survey. Am J Epidemiol. 1987;125:329-39.

7. Sonne-Holm S, Sørensen TI, Jensen G, Schnohr P. Influence of fatnesS, intelligence, education and sociodemographic factors on response rate in a health survey. J Epidemiol Community Health. 1989;43:369-74.

8. Shahar E, Folsom AR, Jackson R. The effect of nonresponse on prevalence estimates for a referent population: insights from a population-based cohort study. The atherosclerosis risk in communities (ARIC) study investigators. Ann Epidemiol. 1996;6:498-506.

9. Korkeila K, Suominen S, Ahvenainen J, Ojanlatva A, Rautava P, Helenius H, et al. Non-response and related factors in a nation-wide health survey. Eur J Epidemiol. 2001;17:991-9.

10. Lundberg I, Damström Thakker K, Hällström T, Forsell Y. Determinants of non-participation, and the effects of non-participation on potential causeeffect relationships, in the PART study on mental disorders. Soc Psychiatry Psychiatr Epidemiol. 2005;40:475-83.

11. Weisaeth L. Importance of high response rates in traumatic stress research. Acta Psychiatr Scand Suppl. 1989;355:131-7.

12. Haapea $M$, Miettunen J, Läärä $E$, Joukamaa $M I$, Järvelin $M-R$, Isohanni MK, et al. Non-participation in a field survey with respect to psychiatric disorders. Scand J Public Health. 2008;36:728-36.

13. Grievink L, van der Velden PG, Yzermans CJ, Roorda J, Stellato RK. The importance of estimating selection bias on prevalence estimates shortly after a disaster. Ann Epidemiol. 2006;16:782-8.

14. Lewin A, Brondeel R, Benmarhnia T, Thomas F, Chaix B. Attrition Bias related to missing outcome data: a longitudinal simulation study. Epidemiology. 2018;29:87-95.

15. Goldberg M, Chastang JF, Zins M, Niedhammer I, Leclerc A. Health problems were the strongest predictors of attrition during follow-up of the GAZEL cohort. J Clin Epidemiol. 2006;59:1213-21.

16. De Graaf R, Van Dorsselaer S, Tuithof M, Ten Have M. Sociodemographic and psychiatric predictors of attrition in a prospective psychiatric epidemiological study among the general population. Result of the Netherlands mental health survey and incidence Study-2. Compr Psychiatry. 2013;54:1131-9.

17. Van der Velden PG, Wong A, Boshuizen HC, Grievink L. Persistent mental health disturbances during the 10 years after a disaster: four-wave longitudinal comparative study. Psychiatry Clin Neurosci. 2013;67:110-8.

18. Van den Berg B, Van der Velden P, Stellato R, Grievink L. Selective attrition and bias in a longitudinal health survey among survivors of a disaster. BMC Med Res Methodol. 2007;7:8.

19. Langley JD, Lilley R, Wilson S, Derrett S, Samaranayaka A, Davie G, et al. Factors associated with non-participation in one or two follow-up phases in a cohort study of injured adults. Injury Prevention. 2013;19:428-33.

20. Yu S, Brackbill RM, Stellman SD, Ghuman S, Farfel MR. Evaluation of nonresponse bias in a cohort study of world trade center terrorist attack survivors. BMC Res Notes. 2015;8:42.

21. Stene LE, Dyb G. Research participation after terrorism: an open cohort study of survivors and parents after the 2011 Utøya attack in Norway. BMC Res Notes. 2016;9:57.

22. Heckathorn DD. Snowball versus respondent-driven sampling. Sociol Methodol. 2011;41:355-66.

23. Association AP. Diagnostic and statistical manual of mental disorders (DSM$\left.5^{\circledR}\right)$. American Psychiatric Pub; 2013.

24. Bracha HS, Williams AE, Haynes SN, Kubany ES, Ralston TC, Yamashita JM. The STRS (shortness of breath, tremulousness, racing heart, and sweating): a brief checklist for acute distress with panic-like autonomic indicators; development and factor structure. Ann Gen Hosp Psychiatry. 2004;3:8.

25. Birmes P, Brunet A, Benoit M, Defer S, Hatton L, Sztulman H, et al. Validation of the Peritraumatic dissociative experiences questionnaire self-report version in two samples of French-speaking individuals exposed to trauma. Eur Psychiatry. 2005;20:145-51.

26. Leon AC, Olfson M, Portera L, Farber L, Sheehan DV. Assessing psychiatric impairment in primary care with the Sheehan disability scale. Int J Psychiatry Med. 1997;27:93-105.

27. Sheehan $D V$, Lecrubier $Y$, Sheehan $K H$, Amorim $P$, Janavs J, Weiller $E$, et al. The Mini-International Neuropsychiatric Interview (M.I.N.I.): the development 
and validation of a structured diagnostic psychiatric interview for DSM-IV and ICD-10. J Clin Psychiatry. 1998;59(Suppl 20):22-33 quiz 34-57.

28. Busner J, Targum SD. The clinical global impressions scale. Psychiatry. 2007; 4:28-37.

29. Abenhaim L, Dab W, Salmi LR. Study of civilian victims of terrorist attacks (France 1982-1987). J Clin Epidemiol. 1992:45:103-9.

30. Durodié B, Wainwright D. Terrorism and post-traumatic stress disorder: a historical review. Lancet Psychiatry. 2019;6:61-71.

31. Dyb G, Jensen T, Glad KA, Nygaard E, Thoresen S. Early outreach to survivors of the shootings in Norway on the 22nd of July 2011. Eur J Psychotraumatol. 2014;5(1):23523.

32. Garfin DR, Poulin MJ, Blum S, Silver RC. Aftermath of terror: a Nationwide longitudinal study of posttraumatic stress and worry across the decade following the September 11, 2001 terrorist attacks. J Trauma Stress. 2018;31:146-56.

33. Silver RC, Holman EA, McIntosh DN, Poulin M, Gilrivas V, Pizarro J. Coping with a national trauma: A nationwide longitudinal study of responses to the terrorist attacks of September 11th. In: Y. Neria, R. Gross, R. Marshall, \& E. Susser. 9/11: Mental health in the wake of terrorist attacks. New York: Cambridge University Press; 2006. p. 45-70.

34. Ghuman SJ, Brackbill RM, Stellman SD, Farfel MR, Cone JE. Unmet mental health care need 10-11 years after the 9/11 terrorist attacks: 2011-2012 results from the world trade center health registry. BMC Public Health. 2014;14:491.

35. Reibman J, Liu M, Cheng Q, Liautaud S, Rogers L, Lau S, et al. Characteristics of a residential and working community with diverse exposure to world trade center dust, Gas, and Fumes. J Occup Environ Med. 2009;51:534-41.

36. Tracy M, Hobfoll SE, Canetti-Nisim D, Galea S. Predictors of Depressive Symptoms Among Israeli Jews and Arabs During the Al Aqsa Intifada: A Population-Based Cohort Study. Ann Epidemiol. 2008;18:447-57.

37. Wood CM, Salguero JM, Cano-Vindel A, Galea S. Perievent panic attacks and panic disorder after mass trauma: a 12-month longitudinal study. J Trauma Stress. 2013;26:338-44.

38. Farfel M, DiGrande L, Brackbill R, Prann A, Cone J, Friedman S, et al. An overview of 9/11 experiences and respiratory and mental health conditions among world trade center health registry enrollees. J Urban Health. 2008;85: 880-909.

39. Verger P, Dab W, Lamping DL, Loze J-Y, Deschaseaux-Voinet C, Abenhaim L, et al. The psychological impact of terrorism: an epidemiologic study of posttraumatic stress disorder and associated factors in victims of the 19951996 bombings in France. Am J Psychiatry. 2004;161:1384-9.

40. Jehel L, Duchet C, Paterniti S, Louville P, Carli P. Évaluation des troubles psychotraumatiques des victimes d'un attentat terroriste. Une étude prospective. Médecine de Catastrophe - urgences collectives. 1999;2:132-8.

41. Bazin F, Parizot I, Chauvin P. Original approach to the individual characteristics associated with forgone healthcare: a study in underprivileged areas, Paris region, France, 2001-2003. Eur J Pub Health. 2005;15:361-7.

42. Massalou D, Ichai C, Mariage D, Baqué P. Terrorist attack in Nice - the experience of general surgeons. J Visc Surg. 2019;156:17-22.

43. Suliman S, Mkabile SG, Fincham DS, Ahmed R, Stein DJ, Seedat S. Cumulative effect of multiple trauma on symptoms of posttraumatic stress disorder, anxiety, and depression in adolescents. Compr Psychiatry. 2009;50: $121-7$.

44. Green BL, Goodman LA, Krupnick JL, Corcoran CB, Petty RM, Stockton P, et al. Outcomes of single versus multiple trauma exposure in a screening sample. J Trauma Stress. 2000;13:271-86.

45. Galea S, Tracy M. Participation rates in epidemiologic studies. Ann Epidemiol. 2007;17:643-53.

46. Thornton L, Batterham PJ, Fassnacht DB, Kay-Lambkin F, Calear AL, Hunt S. Recruiting for health, medical or psychosocial research using Facebook: systematic review. Internet Interv. 2016;4:72-81.

47. Orionzi DE, Mink PJ, Azzahir A, Yusuf AA, Jernigan MJ, Dahlem JL, et al. Implementing a community-driven research partnership: the backyard initiative community health survey methods and approach. Prog Community Health Partnersh. 2016;10:493-503.

48. Reifels L, Pietrantoni L, Prati G, Kim Y, Kilpatrick DG, Dyb G, et al. Lessons learned about psychosocial responses to disaster and mass trauma: An international perspective. Eur J Psychotraumatol. 2013;4(1):22897.

\section{Publisher's Note}

Springer Nature remains neutral with regard to jurisdictional claims in published maps and institutional affiliations.

\section{Ready to submit your research? Choose BMC and benefit from:}

- fast, convenient online submission

- thorough peer review by experienced researchers in your field

- rapid publication on acceptance

- support for research data, including large and complex data types

- gold Open Access which fosters wider collaboration and increased citations

- maximum visibility for your research: over $100 \mathrm{M}$ website views per year

At $\mathrm{BMC}$, research is always in progress.

Learn more biomedcentral.com/submissions 